\title{
E-Book Readers Come to Eastern North Carolina
}

\section{The authors describe a pilot project where Amazon Kindle and Barnes \& Noble Nook e-book readers are provided for patrons to check out. Topics covered include start-up considerations, issues with selection and acquisition of content, cataloging approaches, circulation procedures, publicity strategies, and evaluation.}

$\mathrm{E}$ ast Carolina University (ECU) is the third largest university in the University of North Carolina (UNC) system, with over 27,000 students and over 5,000 staff and faculty. ECU is considered a Doctoral/Research university in the Carnegie Scheme. J.Y. Joyner Library serves as the main campus and Laupus Health Sciences Library serves the medical campus. ${ }^{1}$

Joyner Library began a year-long pilot project to provide library users exposure to hand-held e-book readers in the spring of 2010. Prior to this pilot, the library had purchased a Sony Reader and an Amazon Kindle, and those devices were preliminarily tested in-house by selected staff. Starting in May 2010, one Kindle2, two first generation Barnes \& Noble Nooks, and two first generation iPads were purchased. Over the summer of 2010, these devices were used by a wider number of staff to gain familiarity with them, get a chance to make comparisons, and provide a basis from which to plan for a public program to lend them to library users. Calls were made to neighboring academic libraries (specifically, Duke University and North Carolina State University) that already had similar programs underway, so reinventing the wheel could be avoided. Additional devices of each brand were purchased over the summer. In November 2010, Joyner Library began circulating six Kindles and six Nooks. Starting January 2011, ten iPads began circulating. In addition, four Nook Colors and 13 iPad 2's were purchased in the spring of 2011.
Collaboration across several functional areas was required in order to get the pilot up and running. Personnel in Library Technology (LT), Collections and Technical Services (CD \& TS), the Circulation department (part of the Public Services division), and Library Administration (specifically the Marketing \& Public Relations Manager) all had a hand in the successful launch of the pilot. A number of interested volunteers from other areas contributed as well.

The actual roll-out to the public occurred in the fall of 2010 and winter of 2011 after a period of exploration and experimentation over the summer. Those involved in the pilot spent the summer becoming familiar with the devices and developing procedures for adding content. In August a "petting zoo" event was held to acquaint campus staff and faculty with the devices.

As the pilot progressed, a number of key issues were identified that needed further clarification and monitoring since it became abundantly clear that this technology was definitely in its early stages and was in great flux. The Assistant Director for Collections and Technical Services assumed a leadership role for keeping abreast of the changing landscape for this technology (during this time, a national search was ongoing for an Assistant Director for Library Technology).

What follows from this introduction is a summary of the key areas where we learned many valuable lessons about managing this technology, especially in how it impacts staff who are not necessarily equipped initially to deal with it. Fortunately, this pilot proved mostly exciting and interesting to the personnel who were involved with it. Of course, naturally, there were frustrations and insights that led us to wonder what we had gotten ourselves into! The contributors to this article will in turn document and describe some of these challenges with the hope that the end result may be insightful to others in our state, region, and beyond who wish to embark on a similar program. It is important to note that our early adoption of this technology led us to make conclusions that may after some time seem out-ofdate as the environment changes. But the process by which we proceeded with this experimentation, and the collaborative aspects of our efforts, may be the most useful part of the story. So let the story begin...

\section{Device purchase, set-up, acquisition of titles and cataloging} It was during the initial months of the project that responsibility for each part of the workflow to acquire the e-readers, get them ready for circulation, add content, and make the catalog records accessible to patrons, was tested and finalized. Purchasing and readying the e-readers followed the workflow outlined below.

We decided to consider the e-readers to be pieces of equipment like laptops and digital cameras that the library circulates; therefore personnel in the IT Operations (IT Ops) section of the Library Technology division ordered the e-readers and paid for 
them with a university credit card. Upon delivery, they unpacked and charged them, entered them into the library's equipment inventory, registered them with Amazon or Barnes \& Noble, and put them in a carrying case with a charger and instruction booklet.

The IT Ops staff was also responsible for setting up the devices with the ability to tap into the university's Wi-Fi network. For some devices this was simpler than for others. For example, at the time we purchased our Nook Colors, we had to go off campus in order to set up and register the device. We needed a Web browser to view the authentication screen to $\log$ in to Joyner's Wi-Fi network, but we couldn't launch a browser until the device was registered. The IT Ops staff negotiated with campus Information Technology and Computing Services to waive the login requirement for these wireless devices; registering newly purchased Nook Color devices no longer has to occur off campus.

Should a device subsequently be reported as having equipment-related issues, it is returned to IT Ops where staff will troubleshoot the problem and take appropriate action. If a device is deemed as needing repair or replacement, then IT Ops staff makes arrangements with the vendor; prepares the device to ship out; and in the case of a replacement, removes it from the equipment inventory list.
Due to the nature of it being a pilot project and that requesting university email accounts can be a laborious process, we created unique Google e-mail (gmail) accounts to register the e-readers with their respective vendors and to manage the messages associated with purchasing content. One gmail account was created specifically for the Kindles; and because we initially believed that each device needed a unique email, two gmail accounts were created for each Nook. Upon discovering that a single email account can be linked to multiple devices if the same content is being loaded onto all of them, the second Nook gmail was deemed unnecessary and was deleted.

The e-readers then passed to personnel in the ILS Services section of Library Technology where barcodes and security strips are applied and a call number record for each device is appended to the equipment title record in the Library's online catalog. There is one equipment title record for the Nooks and one for the Kindles.

These equipment records represent one of the discovery points for patrons searching our catalog for the e-readers. The second discovery point is content title records as described later in the article. The equipment title records are created to serve several functions. The first is that it is styled after the equipment title records already present in our catalog for laptops, digital cameras, and other non-book items available for patron check-out and it links to a circulation policy code that defines borrowers, loan periods, fines, etc. Another reason for the creation of an equipment title record is so that a patron who is familiar with the pilot project could search by the name of the e-reader, rather than any particular title loaded on it, see how many e-readers were available for check-out, and place a hold if desired. A final reason for the creation of an equipment title record is so that it can act as an umbrella title that the e-book titles are linked to via the online catalog's "bound with" feature.

Prior to the fall semester roll-out it, was decided that iPads would be removed from the e-reader pilot and would instead be circulated like laptops, with no paid content associated with them. This was because in order to purchase content, an iTunes account must be maintained. The amount and variety of content available through this channel is not as plentiful compared to that of the other two suppliers, and the pricing is different and oftentimes more expensive. As it is, there are more than enough differences between the Kindles and Nooks to keep track of? We also discovered that using the iPads to access Kindle or Nook content we had paid for only served to use up valuable licenses, so we did not offer that option. However,

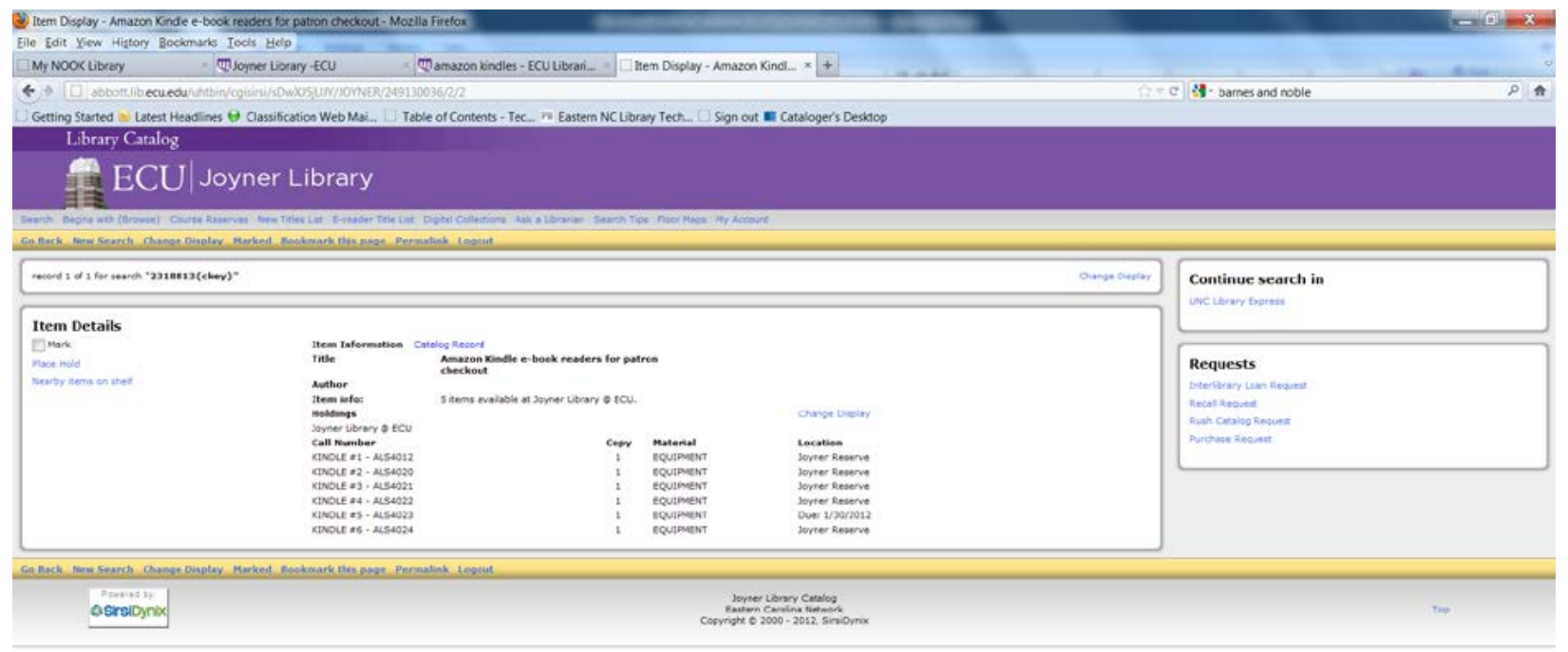


when patrons check out iPads they could access their own e-book content from their own Kindle or Nook accounts if they choose. When iPads are returned after circulating, their set-up is wiped clean and reloaded fresh to remove extraneous downloads and nonstandard content.

Choosing content for the e-readers was the next step. The Collection Development and Acquisitions department heads met with the Assistant Director for Collections and Technical Services to discuss what types of content to purchase and how much money to spend on the pilot project. We chose titles similar to content selected for the library's Popular Reading Collection because the e-readers have a two week loan period, which is the same circulation length as the Popular Reading Collection, and because those titles were typically available from Amazon and Barnes \& Noble for around \$9.95 each. During the pilot project we purchased some titles that cost either a little more or a little less than \$9.95; however, we calculated our initial budget for purchasing content by using $\$ 9.95$ as our baseline price.

Having genre-based e-readers was briefly discussed; for example, a mystery Kindle or a science fiction Nook. This idea was quickly dismissed due to cost, decreased access to patrons, and account management complications. The pricing models for the content allow for titles to be loaded onto multiple devices. It costs the same whether we loaded a title onto one Kindle or six Kindles. With Nooks, the maximum number seemed fungible - we are managing 10 Nooks and are able to load titles on all of them. If a mystery title were loaded onto one device, the advantage of five or more other uses would be lost while at the same time limiting patron access. A patron would have to wait for a particular device to be available for check out rather than being able to check out any one of six Kindles or ten Nooks, all loaded with the same titles. Further, if different titles were loaded onto each, multiple gmail accounts would be needed, as described earlier, to register each device separately, and multiple Kindle and Nook accounts to purchase the titles separately. Keeping track of 12 (later 16) gmail accounts and their associated Kindle and Nook accounts was not practical. With the exception of nine titles available for Kindle that were not available for Nook, the 16 e-readers all have the same content. As of December 2011, the Kindles and Nooks have a total of 81 unique titles offered on them. Since July 2010, the library has spent $\$ 707.72$ on these titles (over a period of two fiscal years).

Since the beginning of this pilot project, it has been discovered that both Amazon ${ }^{2}$ and Barnes \& Noble ${ }^{3}$ now offer schools different methods of managing content on institutionally-owned devices on a larger scale. Discounts can be had if managing many devices, but the pricing model in that case is strictly one-to-one.

One decision made early in the pilot project and then subsequently partially reversed was how to deal with free titles loaded onto the e-readers while they are checked out. One of the security pitfalls with circulating e-readers to patrons is their ability to add a variety of content to the device. While able to deactivate credit card information so that patrons cannot make purchases of content and charge it to the library, patrons can and do download free titles onto the e-readers they have borrowed. Later in this article, the process by which members of our Circulation Department remove content from the devices as well as load new content purchased by the library onto the devices is discussed. In regard to free titles added to the e-readers by patrons, our initial thought was that if the added title was appropriate and of interest to future patrons, we would leave it on the device and add the title to the catalog record. As described in the section on cataloging, the constant addition of free titles to the cataloging record soon threatened to make the records unwieldy, so we stopped doing that and removed most that had been previously added.

As regular users of the Amazon and Barnes \& Noble websites to purchase traditional books for the library, we knew it was possible to tie a university credit card (Visa) to the accounts to pay for titles. However, we encountered two major frustrations when trying to buy content. The first of these is sales tax. East Carolina University is a state institution and has an exemption from paying state sales tax. When creating accounts to purchase traditional books from Amazon or Barnes \& Noble, it was possible to provide a copy of our tax exemption certificate, and then future purchases were automatically exempt. We did not have that option with the accounts for Kindle and Nook content, and the procedures are slightly different for the two suppliers. The library is charged sales tax on some Kindle titles and on all Nook titles. We can request tax refunds from Barnes \& Noble. Requesting tax refunds involves multiple email requests, causes extra paperwork, and may take several weeks to be posted to the credit card statement. The inability to get tax refunds from Amazon not only causes extra paperwork, but also requires documentation to our university accounts payable office that we tried in good faith to obtain a tax refund but were unable to do so. Since beginning the pilot, the library has been given a special exemption from the university so that we do not have to repeatedly and fruitlessly request tax refunds from Amazon. At some point the university will batch the requests and ask for a single refund. Thus far the library has paid less than $\$ 20$ in sales tax to Amazon, but having the exemption has made a huge difference in keeping the work flow manageable.

The second major frustration in the acquisitions realm is the one-title-at-a-time purchase model on the supplier websites and the inability to put multiple titles into a shopping cart and check them out as a single transaction. In order to buy four titles, one is forced to do four transactions with four different receipts. Separate transactions complicate the acquisitions workflow in two ways. One complication is that each separate receipt requires a coordinating separate invoice be created in our integrated library system's acquisitions module to track the expenditure of the funds. The other complication is that transactions on our credit cards require end of the month reconciling in a Bank of America software system. Each transaction to be reconciled involves verifying and/or editing information in three windows and multiple clicks of the mouse. It is a true annoyance that the ordering of Kindle and Nook titles cannot be streamlined in some way to allow for multiple titles to be purchased in one transaction. One of this article's authors, Eleanor I. Cook, has written a chapter in an e-book theme issue of Library Technology Reports which provides greater detail about the sales tax and one-title-at-a-time purchase 
pitfalls facing institutional customers. ${ }^{4}$ It is fair to say that the amount of extra manipulation caused by this arrangement has significantly slowed the number of book titles we are putting on the devices.

In spite of frustrations with the vendor websites for purchasing Kindle and Nook content, a variety of titles were purchased and were able to be reflected as expenditures in the acquisitions module of our integrated library system. In addition, as described below, the Cataloging department was experimenting with different types of bibliographic records and different ways to create discovery points for patrons. Standard practice at our library is for Acquisitions to download (when available) a full bibliographic record from OCLC at the point of purchase order creation and for Cataloging to later overlay it. Since it was unclear what type of bibliographic record Cataloging would eventually use, it was agreed that, for the purposes of the pilot project, order records would not be overlaid or otherwise linked to the final catalog record. To ensure that there were multiple ways to retrieve the cost and title information for the e-reader content, Kindle and Nook vendors were created in our ILS and were used to create one purchase order for the Kindle titles and one for the Nook titles. To populate the purchase order lines, brief bibliographic records were created that contained a 245 title field and a 590 local note field. In addition, content for these fields were standardized.

For example:

245 Picking Cotton (Nook Content) 590 Content for Nook

Likewise, for Kindles the records are as follows:

245 Picking Cotton (Kindle Content) 590 Content for Kindle

The brief bibliographic records are shadowed in the ILS so that they are not visible to patrons, yet Acquisitions staff members conducting pre-order searching can find them to avoid duplicate purchases. Each brief record creates a line in the purchase order where price and fund information are assigned. After the title is successfully downloaded onto the e-reader, the purchase order lines are marked as received and the receipt from the Amazon or Barnes \& Noble website is used to invoice the title and mark it as paid in the ILS. Each purchase order is used for the entire fiscal year; as new titles are bought, additional brief records are created and a line is added to the purchase order. At the start of the next fiscal year, a new purchase order for each brand of device is created using the same criteria as outlined above.

After the initial Kindle and Nook titles were purchased, Cataloging had to ensure that patrons could find them. At first, all the titles were purchased outside of the Acquisitions workflow. Since normal cataloging practice is to overlay existing order records in the online catalog, cataloging was delayed until the orders could be added to the ILS. For the short term, a contents note listing the individual titles was added to the equipment records for the Kindles and Nooks. This seemed a satisfactory solution at first, but the contents note field is not indexed in the title browse index in the online catalog and therefore these titles can only be found via keyword, making discovery difficult for patrons. To counteract this, alternate title entries (740 2) were added for each title. Since it is possible for patrons to download free titles to the Kindles, it quickly became apparent that adding an alternate title entry for each title was threatening to make the bibliographic records unwieldy.

After viewing NC State University's method of linking titles to their respective Kindles (using the same ILS that ECU uses), we contacted them to inquire how this was done. Vendor-supplied documentation for how this process works is so confusing that our colleague at NCSU created web pages, complete with snapshot illustrations, to help convey the convoluted process involved. After some experimentation in the ECU online catalog's test database, it appeared it would be less confusing for patrons if both the Kindles and the Nooks were linked to a single title record. The plan was to use vendor neutral e-book records and add fields to specify the need for an e-book reader and which kind was needed.

In the meantime, the determination was made not to worry about linking the orders to the catalog records. However, having to catalog titles sight unseen, without having an e-reader on which to view them, was problematic. It was possible to view information about each title on the Amazon and Barnes \& Noble web sites, but that was not as good as actually seeing the title pages. Since the e-readers were circulating heavily, the cataloger chose to put a hold on one of the devices in order to see the information as a patron would see it. Since that time, it has been discovered that it is possible to view Kindle content through the Amazon web site, but Nook content is still only available using a Nook e-reader or a tablet e-reader application.

In order for the e-book reader titles to be discoverable in WorldCat, they would need to have ECU's holdings added in OCLC. However, revising a vendor-neutral e-book record to reflect our e-reader titles seemed misleading because it would require removal of the 856 link, additional information about a carrier (the e-book reading device) that standard e-books do not need, and often involved completely different publishers. To further complicate matters, there are significant differences between the e-readers for the same title. Such differences not only made the use of a vendor-neutral e-book record seem impractical, but also required the use of the same record for both Kindle and Nook e-books. At this point, it was decided to use separate records for all titles on both the Kindles and the Nooks, until such time as a provider-neutral e-book record for e-reader e-books was developed.

After beginning to catalog almost all of the Nook titles originally (which was unexpected), it was decided to re-examine the provider-neutral approach. The ProviderNeutral E-Monograph MARC Record Guide suggests that even e-books that require e-readers can use a provider-neutral record, which means there is no need for development of an e-reader provider-neutral record. ${ }^{5}$ The provider-neutral record, as it already exists, de-emphasizes the differences in e-book publishers by concentrating on the content to be found in the record for the original, generally print, copy of the work. This has alleviated the necessity of looking at an actual title page to catalog these e-book titles; the descriptive information found at the vendor web sites provides enough information for 
creation of a provider-neutral record. Also, a true provider-neutral record can be added to OCLC that contains no links or references to carriers. In re-searching the titles in OCLC, all but a handful had e-book records that could be reasonably edited for use with the library's titles. In a recently published article in Library Resources \& Technical Services, catalogers at Oregon State University found that the provider-neutral record approach to cataloging e-book titles on e-readers seems like the best strategy. ${ }^{6}$

Locally, the following fields are being added to the records to bring out the need for the e-book reader at our library to access these titles:

\section{Ebook reader ed.}

538 Requires Barnes \& Noble Nook [or] Amazon Kindle e-book reader [either or both depending on whether the book is on one or both readers]

7102 Barnes \& Noble.

[if applicable]

7102 Amazon.com (Firm)

[if applicable]

This approach allows one bibliographic record to be used per title, even if the e-book is on both the Nooks and the Kindles, reducing the display confusion that can result from multiple records for the same title. To see an example, search Picking Cotton in ECU's online catalog. It was recently discovered that linking new titles to the equipment records for the Kindles and the Nooks was causing those e-book titles to appear first to patrons who were searching for equipment, which includes iPads and laptops, as well as the e-book readers. An editing trick applied to the equipment publication dates allowed the equipment to list first again. However, it appears that separate records for e-book titles might not be the best solution. Besides the problem with the equipment search, linking each e-book title record to as many as 16 e-readers is laborious and time-consuming. Equipment records with formatted contents notes that are properly displayed by the online catalog may be another option.
At the beginning of the pilot project, Collections and Technical Services members loaded all the titles on to the 12 e-readers prior to their being made available for check-out for the first time. After the initial rollout with a baseline collection of titles, the responsibility for downloading new content onto the e-readers was carried out by the Circulation staff member charged with e-reader coordination. Notification of new content purchased was communicated to all stakeholders by an email message from the Assistant Director for Collections and Technical Services to members of the Cataloging and Circulation departments.

\section{Public roll-out of the devices}

At the beginning of the rollout in the fall of 2010, the library had added a collection of approximately three dozen bestsellers on to each device, consisting of a mix of fiction and non-fiction. All e-readers circulated for fourteen days. Up to three renewals are allowed and patrons are able to place holds on e-readers. Normally only a few patrons were on the wait list for either device. A user guide, power cord/charger, and carrying case are included when an e-reader is checked out. A Circulation staff member reviews all of the items checked out with the patron who signs an agreement to return all items in good condition.

Between November 2010 and May 2011, e-readers went out with a paper questionnaire so that users could respond about what they liked and did not like about the experience. Data gathered from this questionnaire is discussed later in this article.

There is an important key distinction between Kindles and Nooks when managing the security aspect of content. With Kindles, it is possible for anyone to load free content from Amazon onto the device, even when the credit card information is deactivated from the account. This free content is usually classic literature in the public domain and games such as Suduko or Chess. With Nooks, any content, regardless of whether it is free or at a cost, cannot be loaded directly from Barnes $\&$ Noble unless the credit card is activated at the website. Because of this variation, there are slightly different routines associated with the upkeep of the devices. In addition, there are minor variations between the original Nooks and the newer color versions in how they are manipulated, although they are all connected to the same Barnes \& Noble account.

As Nook e-readers are returned, the E-reader Coordinator in the Circulation department logs into the Barnes \& Noble account from a desktop computer. The staff member activates the default credit card, which is normally kept turned off so that patrons who have an e-reader checked out cannot purchase new content using the library's account. During these moments when the credit card is activated, anyone with one of the ten Nooks would be able to purchase and/or download material, but the chance of this occurring is almost nil. While the credit card on the account is activated, the E-reader Coordinator checks for new Barnes $\&$ Noble content which has been purchased by the Collection Development department. As the MyLibrary function synchronizes, new content is automatically pushed to the four Nook Color devices. However, this content must be synched individually to the six original Nooks. Once the new content is delivered, usually within a few seconds, the default credit card used by the library to purchase new content is then deactivated.

The process is similar for adding content to the Kindle e-readers. When devices are returned, the E-reader Coordinator logs into the account to check for new content. The biggest difference between the two brands of e-readers is that there is no need to log into the Library's Kindle account via a desktop computer; the account is able to be accessed from the device itself. Once a Wi-Fi connection is established, the Kindle is synchronized and new content is downloaded to the individual device, though not to all six of them at once.

Naturally, patron mischief and unintentional accidents are a concern. The Nooks have up to nine folders in the "My Files" directory variously named "Documents," "Music," "Pictures," etc. These unrestricted folders are able to hold mp3's, images, and other files such as PDF's and Word documents. The E-reader Coordinator must check the folders for any content loaded by the last patron and delete it. The original Nooks do not have to be tethered to delete content, but the Nook Colors must be tethered to a desktop computer to erase patron 
loaded content. While the Kindle's ability for patrons to load content to folders is not as extensive as the Nook's, any PDF's or "My Clippings" loaded by patrons must also be wiped clean as devices are returned. Like the original Nooks, the Kindle does not have to be tethered to erase patron loaded content. However, an interesting feature of the Kindle is the ability for patrons to de-register and reregister the devices. Once in a patron's hands, the Kindles can be de-registered and then reregistered under a patron's personal account simply by visiting the "Settings" function. Once re-registered under a personal account, the Kindle can then be loaded with any patron purchased content. Once the device is returned and the E-reader Coordinator notices the registration activity, she can easily repeat the process of de-registering and re-registering the Kindle under the library's account. Thankfully, this has only happened three times. While all of this maintenance activity costs staff time, so far patron activity with loading content or de-registering devices has not been a significant problem; therefore, at the present time the library does not attempt to notify patrons that their "mischief" has been noticed and corrected. The E-reader Coordinator maintains a spreadsheet each time a device is returned with the date and any notes regarding reloaded content, software updates, or file deletions.
As noted in the section discussing acquisitions and cataloging of content, we were not quite sure what we wanted to do about free content that was loaded by patrons. At the end of the spring semester 2010, as we were assessing the pilot, we decided that selected free "classics" that were downloaded along the way were worthy of keeping on the e-readers. The Assistant Director for Collections and Technical Services ultimately determines which free content is kept and notifies everyone in the information chain who needs to know about new content. All other content that has not been intentionally chosen is deleted, either as a device returns from circulation or at the end of a semester.

Miscellaneous considerations for maintaining a circulating collection of e-readers include keeping a supply of spare parts and carrying cases. ECU's Joyner Library keeps back up chargers for both brands of e-readers. Circulation staff members are instructed to alert the staff in the IT Ops deptment if an e-reader is returned damaged, is missing equipment, or otherwise is not functioning correctly. To date there have been more than 250 checkouts and both the e-readers and ancillary equipment have been returned in good condition. Naturally, there have been some signs of normal wear and tear, especially with the power cords, which are fragile. However, as mentioned previously, the amount of patron "mischief" related to content has also been minimal.

\section{Publicity}

Publicity for the e-book reader pilot service was coordinated by Joyner Library's Marketing and Public Relations Manager with assistance from her graduate assistant for graphic design. Emails with an eye-catching digital flyer were posted to campus listservs for students, faculty, and staff. These digital flyers were also loaded onto large plasma screens in the library and in the News \& Events section of the library's Web page. Features ran in the library's e-publications; Joyner Library eNews and ALS Collections, the library's newsletter from Collection Development librarians to liaisons in the academic departments. Articles appeared in the student newspaper The East Carolinian, the campus publication Pieces of Eight, and Greenville's local newspaper The Daily Reflector. Publicity was also posted on the library's Facebook site and Twitter feed. In addition to running features in library and campus publications, in the summer of 2010, we held workshops and sessions where the e-readers were made available for hands-on use. Then at the beginning of the fall semester, a "Petting Zoo" was hosted where staff and faculty of the university were invited to come and check out the devices, with some demonstration, but mostly to get

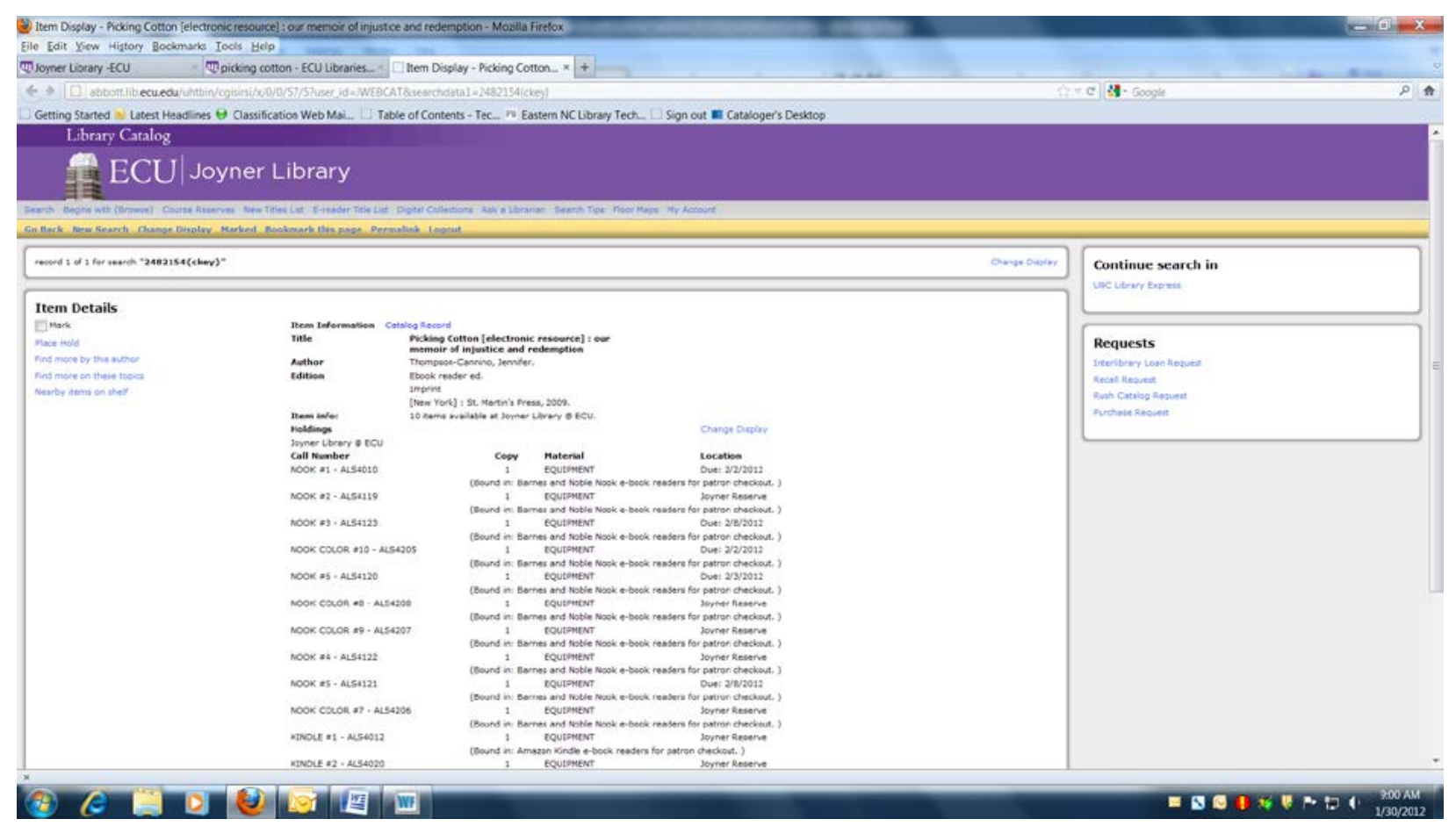


some hands-on experience. Approximately 50 people participated in the petting zoo event.

In March 2011, Joyner Library co-sponsored an e-book/e-reader education exposition called See It! Learn It! Use It! Joyner Library partnered with Laupus Library on the medical campus and the university's Office of Emerging Academic Initiatives. Publishers, e-reader vendors, the university bookstore, and faculty shared their expertise and experiences. This event was open to all students, faculty, and staff.

The publicity that often matters most to library users is word of mouth. People on campus share with each other what they like about the Kindles, Nooks, and iPads they borrow from the library. Press releases, emails, flyers, and events are important, but the best publicity is a good user experience.

\section{E-reader Evaluation}

To gather feedback on use of the e-readers, we designed a brief evaluation for Circulation Department staff to give patrons to complete after returning a device. From 44 responses we learned that $52 \%$ borrowed a Kindle, while $48 \%$ borrowed a Nook. The reasons theystated for borrowing the devices were as follows:

- $80 \%$ Curiosity/Experimentation

- $41 \%$ Compare with another product

- $36 \%$ Test before buying their own

- $\quad 9 \%$ Read a specific book

No surprise that $95 \%$ of the users borrowed an e-reader to read a book. Only 5\% used the device to listen to a book. E-readers were used in the following locations:

- $\quad 98 \%$ At home

- $23 \%$ Traveling (not commuting)

- $11 \%$ In their office

- $11 \%$ In the library

- $2 \%$ Commuting

- $\quad 9 \%$ Other

When asked, "Did the e-reader meet your needs and if so, what did you find most useful?" most Kindle responders expressed a positive experience. Comments included "the reader was great; nice display; booklike appearance; enjoyed its portability and size; read multiple books; I read faster and smoother; good backlighting." However, there were some negative comments about the Kindles, including "selection somewhat disappointing; I will NOT rush out and buy one!" Positive comments about the Nook included "ease of use; met my expectations; easy on my eyes; easier to read than a book." Complaints about the Nook included "did not like it as much as the Kindle; would use for the most basic purposes; fine for trying out."

When asked specifically about e-reader problems, those who borrowed a Kindle said "highlight does not really highlight; lack of features such as custom zoom and text size; freezing and resetting; no backlight; navigation clunky." Nook users told us "navigation problematic; screen jumpy; slow, gave up trying to increase font size; heavier than the Kindle; hard to press the page turn buttons; not great for Internet."

Recommendations for titles to place on the e-readers included fiction and non-fiction on more current events, Christian fiction, history, military history, thrillers, romance, science fiction, bestsellers, and classics. Several respondents requested e-books by specific authors such as Hannah Swenson, Janet Evanovich, James Patterson, Laurel K. Hamilton, Jane Austen, Diana Gabaldon, and North Carolina authors Lee Smith, Michael Malone, Reynolds Price, and Doris Betts. Of course, there was also a request for the Harry Potter series.

Closing comments and suggestions were overwhelmingly positive. A few respondents wanted more devices to choose from, including color readers. One person asked for access to e-books from the library's online catalog. A request for individual student accounts for downloading free e-books was intriguing. Many people used this section to express their appreciation for the trial.

Forty-eight percent of the evaluation respondents were students, $20 \%$ were faculty, $30 \%$ were staff, and $2 \%$ were retired staff.

\section{E-book Reader Awareness Survey}

During the Fall 2011 semester university students, faculty, and staff were sent an online survey to assess the impact of our pilot e-book reader loan service. SurveyMonkey was used to conduct the study. Thirteen percent of survey responders were students, 35\% faculty, and 58\% staff, which included paraprofessionals, non-faculty professionals, and administrators.

Sixty-seven percent of responders were aware that they could borrow Kindles, Nooks, and iPads from the library. However, 83\% had not done so. When asked why they had not borrowed an e-book reader or tablet, 69\% responded that they owned one. Seven percent said the waiting list was too long and 5\% said they were not interested in the content provided. Respondents who did borrowed a device selected Kindles and Nooks equally (4\%). Slightly more (6\%) borrowed an iPad.

Thirty-one percent of those surveyed told us that using the library's device influenced their decision to purchase one. Twenty percent purchased a Kindle, 30\% an iPad, 40\% a Nook, and 20\% another brand. The total purchases indicate that some of our users bought more than one brand of device.

The sample size of this survey was extremely low. Despite broad campus emails, only 46 people completed the survey. With a campus of over 1,000 staff, 5,000 faculty, and 25,000 students, the survey response should be much higher. Although we did offer a raffle of prizes as incentives, we need to explore other strategies for gathering data to assess user satisfaction with the e-book reader service.

\section{What does the future hold?}

It is unlikely that Joyner Library will invest in additional e-reader devices for the time being, although the e-readers we do have continue to circulate regularly. Instead, it seems clear that libraries should be offering e-book content that can be read on a variety of devices that patrons own themselves. The Overdrive and 3M model works this way. Through such a platform, the library can provide content via the vendor interface, which supports almost every type of e-book reader and tablet. There continue to be several challenges, however. One challenge is limitations set by publishers. The decision by Harper Collins to limit library circulations to 26 times before the library has to buy a new copy of the e-book is one example. Several other major publishers have stopped making their current books available for library e-circulation at all. Another major issue for 
libraries is whether or not they actually own the content they purchase. A recent interview with the Kansas State Librarian (as presented at the ALA Midwinter Conference in January 2012) suggests that librarians must pay close attention to their license agreement with content providers since platforms may be only offering leased arrangements where content is not actually owned. In the case of the Kansas State Library, quite a bit of effort was expended in order to move platforms so that they could maintain their purchased materials. $^{\text {? }}$

\section{Conclusion}

The introduction of new electronic products into the marketplace has not always been easy for innovators. While many products become wildly successful, others are complete flops. The Library of Congress American Memory optical disk project of the 1990s, the Sony Betamax system, and the original Apple TV are examples of electronic products that failed to gain a toe-hold into consumer markets. The current crop of early e-book readers will no doubt be similar. Some platform types will survive while others will go the route of Sony Betamax. Chamodrankas has noted that these electronic device marketplaces "fail because their structure and mode of operation does not allow for the effective accommodation of multiple business models that could serve the interests of a critical mass of adopters." 8 Our research has verified the thesis of Chamodrankas in that the multiple e-book platform readers fail to accommodate various electronic e-book reader business models. As noted above, both the Kindle and the Nook have failed to provide libraries with an ideal platform model. The failure of the vendors to provide a business model that would enable a critical mass of libraries to adopt their structure and mode of operation will in the short run limit the development of a universal or "neutral" business model. Chamodrankas concludes that the development of this neutral electronic marketplace will "enhance the satisfaction of buyers and sellers by assisting them in the course of their decision making process." If this were to happen it would certainly make the choice between a Kindle or a Nook easier because the electronic content would be liberated from the bonds of platform dependency. The lesson of the Sony Betamax System is there for e-book vendors to learn from.

Given these platform limitations, what did we learn from our e-book reader experience? First of all we learned that library loan of e-book readers can assist library users in the selection of a personal system for purchase. Both the Petting Zoo and Circulation desk loans of readers were accompanied by patron comments about features that they preferred about specific readers. These positive and negative comments undoubtedly influenced future purchases of devices. Second, we learned that vendors were not always as cooperative as they could be regarding the sharing of their e-book products across platforms and with multiple patron use. And third, while one vendor was willing to work with us on refunding sales tax, the other was not as accommodating and in fact would not establish a consistent routine for the refund process at all.

\section{References}

${ }^{1}$ East Carolina University. Factbook, 2010/2011.

http://www.ecu.edu/cs-acad/ipar/CustomCF/DL/FB/FactBook10-11.pdf (Accessed 17 February, 2012)

2 Barack, Lauren. "Amazon Alters Rules for Kindles in School Libraries," School Library Journal, August 1, 2011. http://www.schoollibraryjournal.com/slj/home/891470-312/amazon_alters_rules_for_kindles.html.csp (Accessed 17, February, 2012)

${ }^{3}$ Phone conversation with Barnes \& Noble employee, 12 August, 2012.

${ }^{4}$ Cook, Eleanor I. "Academic Library Dilemmas in Purchasing Content for E-readers: Debit cards, Sales Tax, and Workflow Issues." Library Technology Reports, v.47, no.8, Nov/Dec 2011, p.14-17.

${ }^{5}$ Culbertson, Becky, Mandelstam, Yael, and Prager, George. Provider-Neutral E-Monograph MARC Record Guide. Washington, D.C.: Program for Cooperative Cataloging, 2009 with revisions, September 2011. http://www.loc.gov/catdir/pcc/bibco/PN-Guide.pdf (accessed 17 February, 2012)

${ }^{6}$ Sapon-White, Richard. "Kindles and Kindle E-books in an Academic Library: Cataloging and Workflow Challenges." Library Resources \& Technical Services, v. 56, no.1, January 2012.

${ }^{7}$ http://www.libraryjournal.com/lj/home/892348-264/kansas_state_librarian_can_transfer.html.csp

${ }^{8}$ Chamodrakas, Ioannis. "'Liquid' Electronic Marketplaces," In IFIP International Federation for Information Processing; Project E-Society: Building Bricks, 226:366-379 (2006).

${ }^{9}$ Ibid

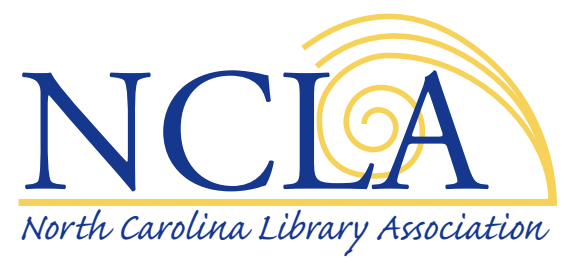

